\title{
SISTEM INFORMASI PENCATATAN DAN PELAPORAN PUSKESMAS PROGRAM KESEHATAN IBU DAN ANAK PADA DINAS KESEHATAN KABUPATEN KUDUS
}

\author{
Intan Risan Sari \\ Fakultas Teknik, Program Studi Sistem Informasi \\ Universitas Muria Kudus \\ Email: Intanrisans19@gmail.com \\ Fajar Nugraha \\ Fakultas Teknik, Program Studi Sistem Informasi \\ Universitas Muria Kudus \\ Email: fajar.nugraha@umk.ac.id
}

\begin{abstract}
ABSTRAK
Masalah kesehatan ibu dan anak (KIA) masih menjadi masalah kesehatan di Indonesia. Hal ini dikarenakan masih tingginya angka kematian ibu dan angka kematian bayi, yang tiap tahunnya mencapai 450 per seratus ribu kelahiran hidup. Tingginya angka kematian ibu dan anak, membutuhan intervensi ataupun pemantauan yang intensif oleh dinas kesehatan melalui fasilitas kesehatan yang tersedia di masyarakat. Pelaporan program KIA pada dinas kesehatan kabupaten Kudus menunjukkan bahwa pencatatan dan pelaporan puskesmas program kesehatan ibu dan anak (KIA) kurang terdokumentasi dengan baik dikarenakan pelaporan yang tidak tepat waktu. Tujuan dari penelitian ini adalah menghasilkan sistem informasi yang berguna dalam menangani proses pencatatan dan pelaporan kesehatan KIA melalui sebuah sistem informasi. Manfaat sistem informasi pencatatan dan pelaporan program kesehatan ibu dan anak ini diharapkan dapat digunakan untuk mengetahui tingkat kesehatan ibu dan anak melalui pencatan dan pelaporan yang lebih teratur dan tepat waktu. Metode yang digunakan dalam rekayasa perangkat lunak (RPL) sistem ini adalah model Waterfall, sementara untuk metode perancangan sistem menggunakan permodelan Unified Modeling Language. Hasil dari penelitian ini adalah sistem informasi pencatatan dan pelaporan puskesmas program kesehatan ibu dan anak pada dinas kesehatan kabupaten Kudus yang dapat digunakan untuk pengelolaan data data SP3 kesehatan ibu dan anak.
\end{abstract}

Kata kunci: pencatatan dan pelaporan, kesehatan ibu dan anak (KIA), sistem informasi.

\begin{abstract}
Problems maternal and child health is still a public health problem in Indonesia. This is because the high maternal mortality rate and infant mortality rate, which annually reaches 450 per hundred thousand live births. The high rate of maternal and child mortality, membutuhan intervention or intensive monitoring by the department of health through health facilities available in the community. Reporting KIA program at district health offices Holy indicates that the recording and reporting of program health centers maternal and child health is less well documented due to a lack of timely reporting. The purpose of this research is to produce a system of information useful in dealing with the process of recording and reporting of health KIA through an information system. The benefits of information systems for recording and reporting maternal and child health program is expected to be used to determine the level of maternal and child health through the paint of and reporting more regular and timely. The method used in software engineering is Waterfall model, while for the method of designing systems using modeling Unified Modeling Language. Results from this study is an information system for recording and reporting health centers maternal and child health program in Kudus district health offices that can be used for data management of data SP3 maternal and child health.
\end{abstract}

Keywords: recording and reporting, maternal and child health, information systems.

\section{PENDAHULUAN}

Penyebab langsung kematian ibu dan anak dapat dicegah jika dapat terdeteksi secara dini melalui suatu manajemen untuk mendeteksi dini penyebab kematian tersebut yang berupa pemantauan atau pencatatan wilayah setempat mengenai kesehatan ibu dan anak [1]. Sistem pencatatan dan pelaporan puskesmas (SP3) digunakan untuk memenuhi kebutuhan administrasi pada jenjang yang lebih tinggi dalam rangka pembinaan, penetapan kebijaksanaan dan dimanfaatkan oleh puskesmas untuk peningkatan 
upaya kesehatan puskesmas, melalui perencanaan, penggerakan, pelaksanaan, pengawasan, pengendalian, dan penilaian [2]. Sistem pencatatan dan pelaporan terpadu puskesmas juga berfungsi untuk petugas di tingkat puskesmas agar lebih bertanggung jawab dalam mencatat seluruh upaya kesehatan yang dilaksanakannya dan melaporkan secara teratur dan tepat waktu serta mampu memanfaatkan data dan informasi dari data sistem pencatatan dan pelaporan terpadu puskesmas sehingga dapat memberikan umpan balik [3].

Sistem pencatatan dan pelaporan puskesmas (SP3) program kesehatan ibu dan anak (KIA) di kabupaten Kudus dalam pelaksanaannya masih terbatas pada rekapitulasi data hasil dari interaksi antara masyarakat pengguna program kesehatan ibu dan anak dengan fasilitas kesehatan (puskesmas), sehingga seringkali data tersebut tidak terdokumentasi dengan baik dan lengkap. Keterlambatan perubahan data atau pelaporan SP3 akan menyebabkan tujuan pelaporan tersebut menjadi tidak tercapai. Berdasarkan hal tersebut maka diperlukan pengembangan sistem pelaporan yakni sistem informasi pencatatan dan pelaporan puskesmas program kesehatan ibu dan anak pada dinas kesehatan kabupaten Kudus. Sistem ini diharapkan akan mengintegrasikan dan menampung perubahan data atau pelaporan program kesehatan ibu dan anak di puskesmas kepada dinas kesehatan menjadi lebih baik.

\section{METODOLOGI PENELITIAN}

\subsection{Metode Rekayasa Perangkat Lunak}

Pendekatan yang digunakan dalam rekayasa perangkat lunak (RPL) sistem ini adalah model waterfall. Rekayasa perangkat lunak adalah pembangunan dengan menggunakan prinsip atau konsep rekayasa dengan tujuan menghasilkan perangkat lunak yang bernilai ekonomi yang dipercaya dan bekerja secara efisien menggunakan mesin [4]. Tahap-tahap dalam model waterfall, yaitu :

a. Analisis kebutuhan perangkat lunak merupakan proses pengumpulan kebutuhan secara intensif untuk menspesifikasikan kebutuhan perangkat lunak agar dipahami oleh user.

b. Desain adalah proses multilangkah yang fokus pada desain pembuatan program perangkat lunak termasuk struktur data, arsitektur perangkat lunak, representasi antarmuka dan prosedur pengkodean.

c. Pengkodean, desain diterjemahkan ke dalam program perangkat lunak.

d. Pengujian, proses yang dilakukan untuk meminimalisir kesalahan (error) dan memasukkan keluaran yang dihasilkan sesuai dengan keinginan.

e. Pemeliharaan, mengulangi proses pengembangan mulai dari analisis spesifikasi untuk perubahan perangkat lunak yang sudah ada, tapi tidak untuk membuat perangkat lunak baru.

\subsection{Metode Perancangan Sistem}

Dalam melakukan perancangan sistem diperlukan pemodelan untuk menggambarkan proses atau kegiatan yang dilakukan dan bagaimana data berpindah diantara proses atau kegiatan tersebut. Salah satu cara untuk merepresentasikan permodelan adalah dengan menggunakan Unified Modeling Language (UML). UML merupakan sistem arsitektur yang bekerja dengan Object Oriented Arcitechture Design (OOAD) dengan satu bahasa yang konsisten untuk menentukan, visualisasi, mengkontruksi, dan mendokumentasikan artifact yang terdapat dalam sistem software [5].

\subsection{Metode Pengumpulan Data}

Metode pengumpulan data yang digunakan dalam penelitian ini adalah sebagai berikut:

a. Metode Observasi, pengamatan yang dilakukan secara sistematis untuk kemudian dilakukan pencatatan dengan menggunakan dan mempelajari praktek-praktek pelaksanaan di tempat penelitian meliputi proses pencatatan dan pelaporan program kesehatan ibu dan anak yang dilakukan oleh fasilitas kesehatan masyarakat.

b. Metode Kepustakaan, sebagai bahan pertimbangan untuk mendapatkan data sekunder yang mengacu pada literatur, buku, diktat, catatan yang dapat menunjang penyusunan penelitian ini.

c. Metode Wawancara, untuk mendapatkan informasi berkenaan dengan sistem yang telah berjalan sebelumnya maka dilakukan wawancara untuk mengetahui permasalahan maupun solusi sementara dapat digunakan dalam menyelesaikan permasalahan dalam proses pencatatan dan pelaporan program kesehatan ibu dan anak. 


\section{HASIL DAN PEMBAHASAN}

\subsection{Analisa Masalah}

Analisa permasalahan digunakan untuk mendapatkan gambaran secara lengkap mengenai permasalahan yang terjadi dalam pencatatan dan pelaporan puskesmas program kesehatan ibu dan anak pada dinas kesehatan kabupaten Kudus. Sejauh ini puskesmas, keterlampatan dalam pelaporan SP3 dan tidak lengkapnya data yang dikirim merupkan permasalahan yang seringkali terjadi, sehingga dalam pengolahan data menjadi sebuah informasi menjadi tidak efektif dan akurat. Untuk mengatasi hal tersebut perlu adanya pengembangan sistem informasi dalam melakukan pencatatan dan pelaporan puskesmas program kesehatan ibu dan anak untuk membantu proses pengolahan laporan SP3 KIA puskesmas kepada instansi terkait dalam hal ini dinas kesehatan kabupaten Kudus.

\subsection{Analisa Kebutuhan Data dan Informasi}

Untuk pengambangan suatu sistem yang baru diperlukan masukan berupa data yang kemudian akan diproses sehingga menghasilkan informasi yang berguna kepada pihak yang membutuhkan. Kebutuhan data dan informasi untuk sistem pencatatan dan pelaporan program puskesmas program kesehatan ibu dan anak sebagai berikut:

a. Data-data yang diperlukan antara lain: data SP3 program kesehatan ibu dan anak, data puskesmas, data pengguna sistem.

b. Kebutuhan informasi yang diperlukan dalam penelitian ini antara lain: Informasi kesehatan ibu dan anak pada semua puskesmas di wilayah kabupaten Kudus, hasil laporan SP3 program kesehatan ibu dan anak perpuskesmas dan per periode pelaporan.

\subsection{Business Use Case Diagram}

Diagram business use case atau use case bisnis menunjukkan interaksi antara use case bisnis, aktor bisnis dan pekerja bisnis dalam sebah organisasi. Diagram ini menggambarkan model lengkap tentang apa yang telah perusahaan lakukan, siapa yang ada di dalam organisasi dan siapa yang berada di luar organisasi [6]. Use case bisnis sistem pencatatan dan pelaporan puskesmas program kesehatan ibu dan anak yang menggambarkan tentang proses yang dilakukan oleh pekerja bisnis dengan use case bisnis secara detail dapat dijelaskan pada gambar 1.

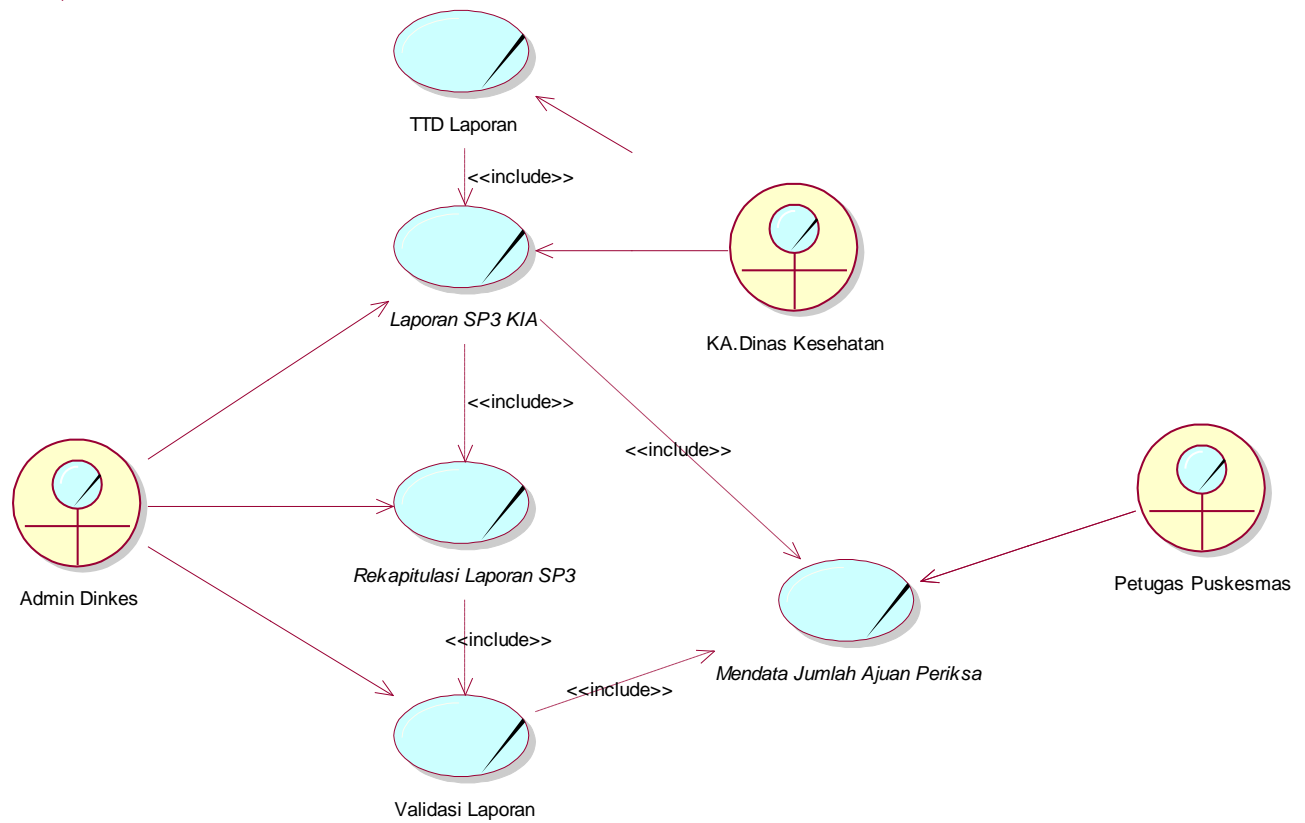

Gambar 1. Business Use Case

\subsection{Use Case Diagram}

Diagram use case menunjukkan beberapa use case dalam sistem, beberapa aktor dalam sistem, dan relasi antar mereka. Use case adalah potongan fungsionalitas tingkat tinggi yang akan disediakan oleh sistem. Aktor adalah seseorang atau sesuatu yang berinteraksi terhadap sistem yang akan dibangun [5]. Adapun penggambaran use case diagram dari sistem informasi pencatatan dan pelaporan puskesmas program kesehatan ibu dan anak secara detail dapat dijelaskan pada gambar 2 . 


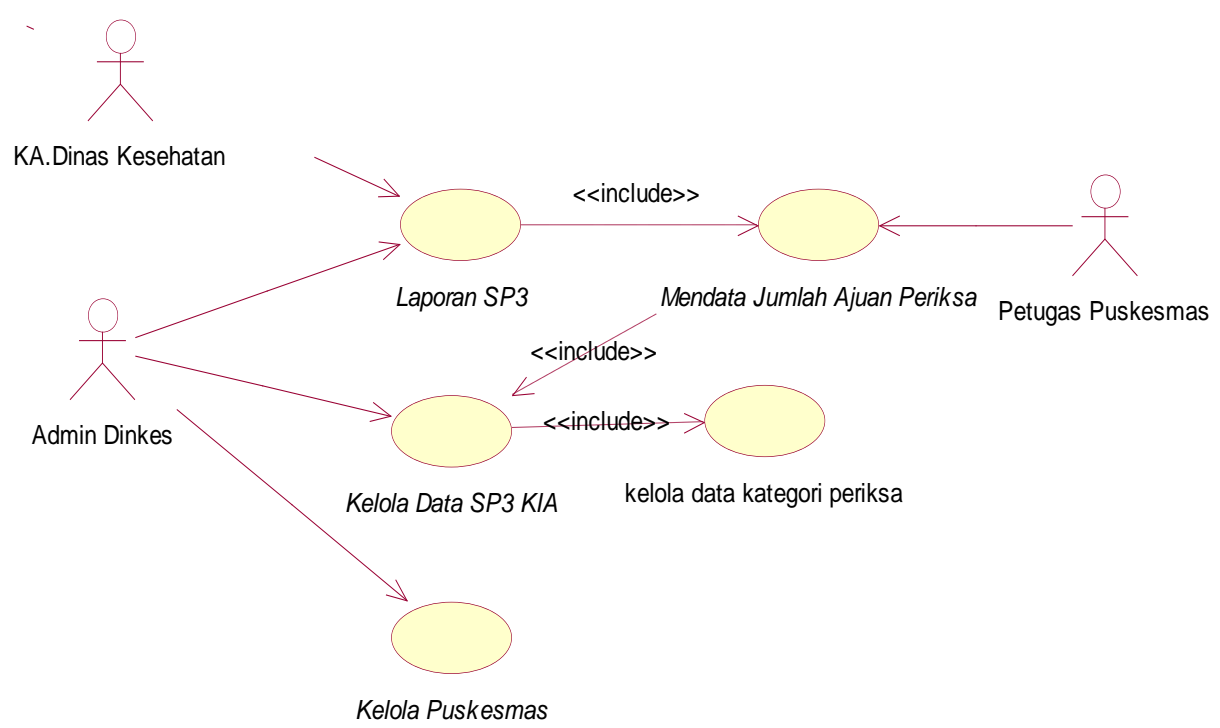

Gambar 2. Use Case Diagram

\subsection{Class Diagram}

Class diagram atau diagram kelas digunakan untuk menampilkan kelas-kelas atau paket-paket di dalam sistem dan relasi antar mereka. Diagram kelas memberikan gambaran sistem secara statis [6]. Gambar 3 berikut ini adalah diagram kelas sistem informasi pencatatan dan pelaporan puskesmas program kesehatan ibu dan anak :

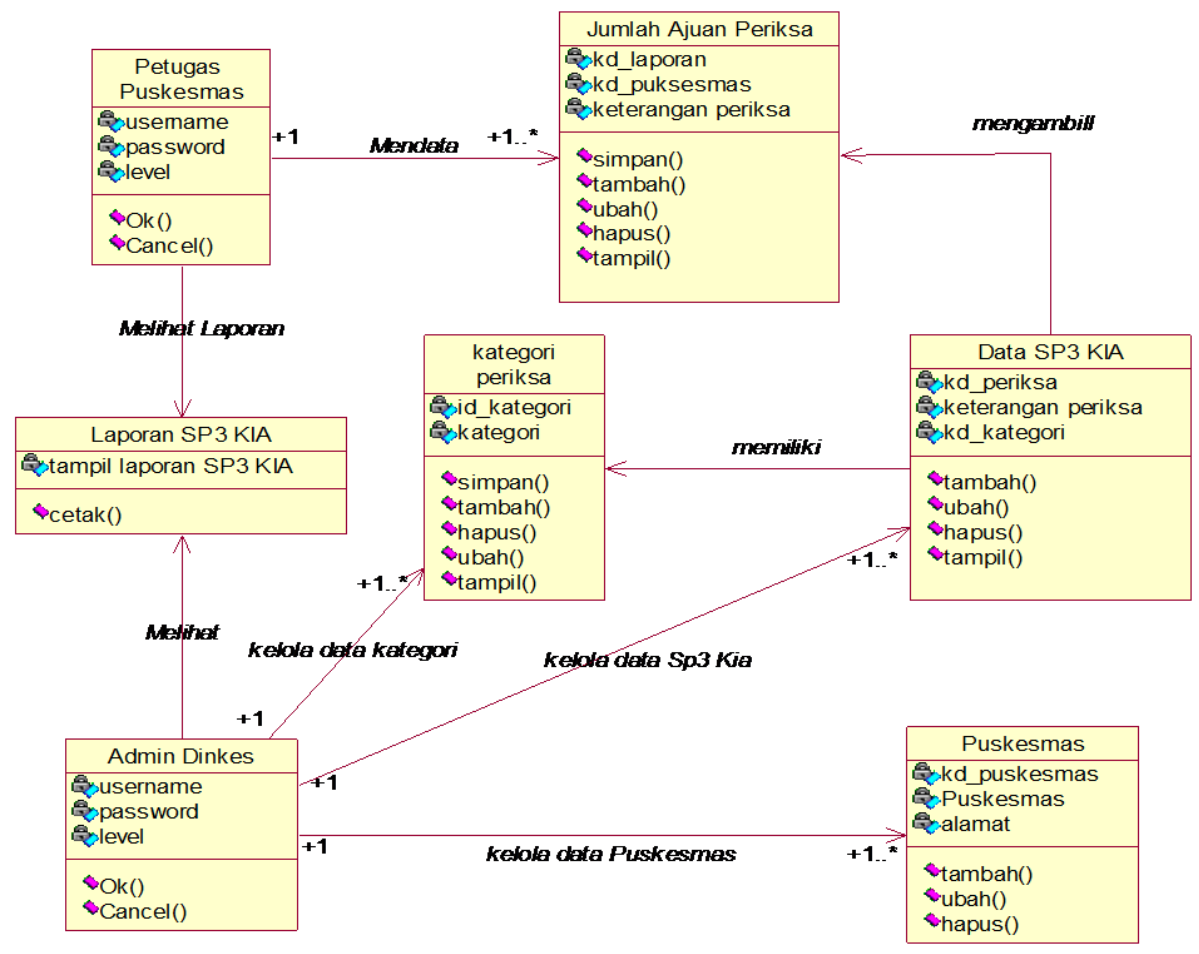

Gambar 3. Class Diagram

\subsection{Perancangan Basis data}

Sebuah sistem informasi tidak akan lepas dari basis data, basis data (database) adalah kumpulan terorganisasi dari data-data yang berhubungan sedemikian rupa sehingga mudah disimpan, dimanipulasi, serta dipanggil oleh pengguna [7]. Tabel yang dipergunakan dalam basis data perancangan sistem pencatatan dan pelaporan puskesmas ini terdapat 5 buah tabel yang digunakan. Adapun desain relasi tabel dari perancangan basis data yang terbentuk berdasarkan kebutuhan data dan informasi dalam penelitian ini dapat dilihat pada gambar 4 . 


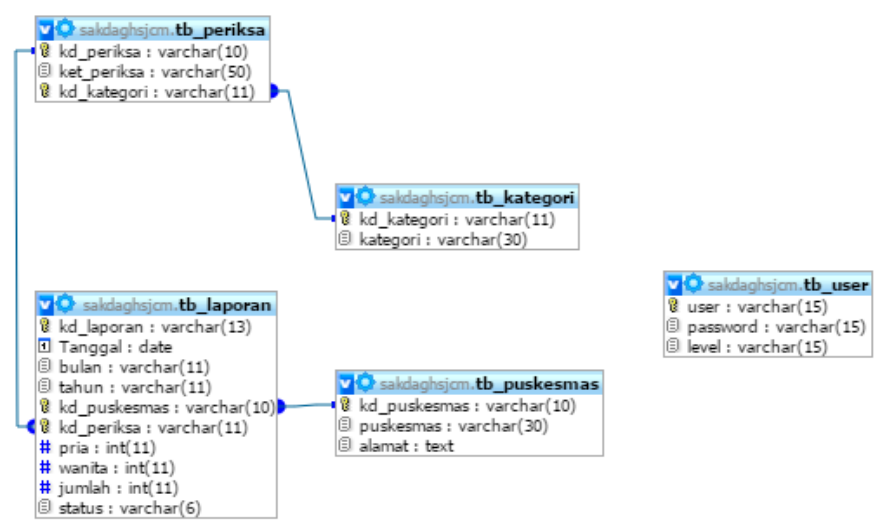

Gambar 4. Relasi tabel basis data sistem informasi pencatatan dan pelaporan puskesmas program kesehatan ibu dan anak

\subsection{Implementasi Sistem}

Implementasi adalah tahapan dari penerapan dan pengujian hasil desain sistem informasi pencatatan dan pelaporan puskesmas program kesehatan ibu dan anak pada dinas kesehatan kabupaten Kudus. Implementasi merupakan salah satu tahapan dalam pengembangan sistem perangkat lunak. Program ini diimplementasikan menggunakan aplikasi Macromedia Dreamweaver 8 dan penyimpanan data atau database MySql. Hasil tampilan antarmuka dari halaman utama sistem informasi pencatatan dan pelaporan puskesmas program kesehatan ibu dan anak pada dinas kesehatan kabupaten Kudus ditunjukkan pada gambar 5.

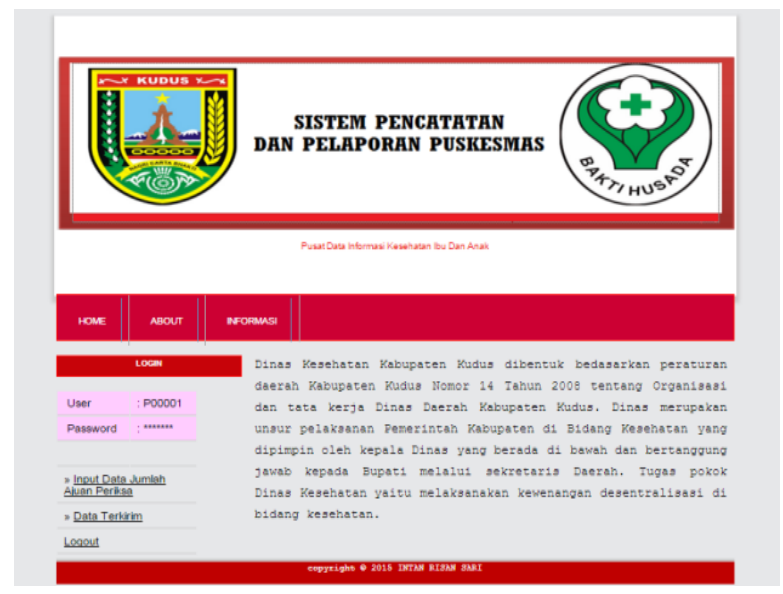

Gambar 5. Halaman utama sistem informasi informasi pencatatan dan pelaporan puskesmas program kesehatan ibu dan anak

Pada gambar 6 memperlihatkan halaman input data pada sistem ini adalah menu utama input data jumlah ajuan periksa. Data yang akan diinputkan dalam sistem meliputi: no, kd_periksa, nama ajuan pemeriksaan. Form ini juga memiliki fungsi untuk menyimpan data jumlah ajuan periksa.

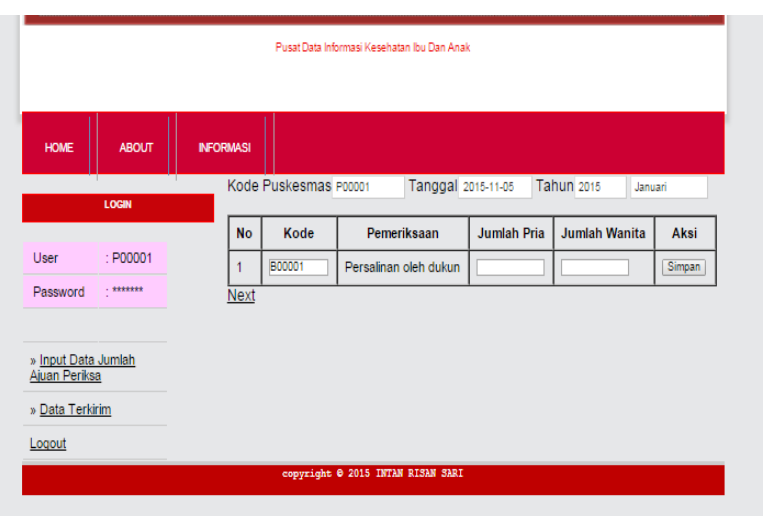

Gambar 6. Halaman input data 
Pada gambar 7 dan 8 menunjukkan Halaman Laporan serta grafik laporan sistem informasi pencatatan dan pelaporan puskesmas program kesehatan ibu dan anak berdasarkan pemrosesan data dari laporan pencatatan dan pelaporan puskesmas program kesehatan ibu dan anak yang sudah diinputkan oleh petugas puskesmas.

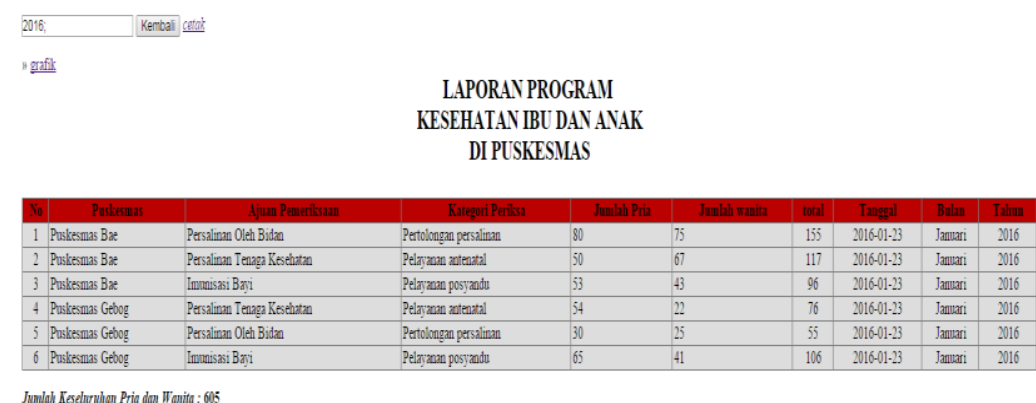

Gambar 7. Halaman laporan sistem informasi pencatatan dan pelaporan puskesmas program kesehatan ibu dan anak

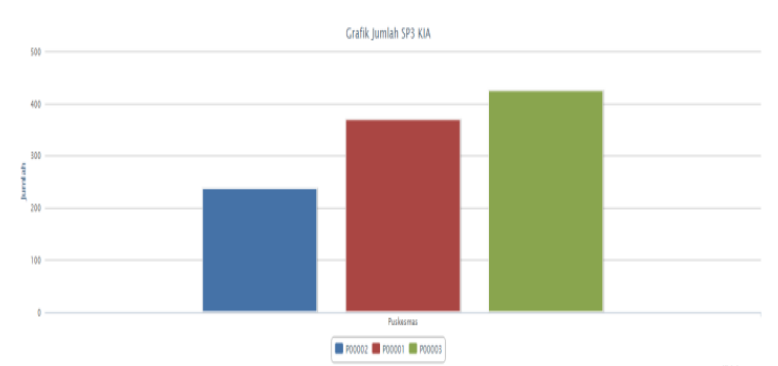

Gambar 8. Halaman grafik laporan sistem informasi pencatatan dan pelaporan puskesmas program kesehatan ibu dan anak

\section{KESIMPULAN}

Dari hasil penelitian dan pembahasan yang telah dilakukan pada sistem informasi pencatatan dan pelaporan puskesmas program kesehatan ibu dan anak di dinas kesehatan kabupaten Kudus, dapat disimpulkan bahwa:

a. Sistem ini memiliki dapat digunakan untuk pengelolaan data puskesmas, mengelola data user (pengguna), mengelola data kategori periksa, mengelola data SP3 KIA, mengelola data jumlah ajuan periksa.

b. Informasi yang dihasilkan meliputi Informasi kesehatan ibu dan anak pada semua puskesmas di wilayah kabupaten Kudus, hasil laporan SP3 program kesehatan ibu dan anak perpuskesmas dan per periode pelaporan.

c. Perancangan sistem pencatatan dan pelaporan puskesmas program kesehatan ibu dan anak berbasis web pada dinas kesehatan kabupaten Kudus ini digunakan pemodelan Unified Modelling Language (UML). Untuk pembuatan aplikasinya menggunakan bahasa pemograman PHP dan basis data MySQL.

\section{DAFTAR PUSTAKA}

[1] Yudhy Dharmawan, Putri Asmita Wigati, Fifi Dwijayanti. 2015. "Kinerja Petugas Dalam Pencatatan Dan Pelaporan Pws Kia Di Puskesmas Duren”. Jurnal Kesehatan Masyarakat, volume 10.2, 210-217.

[2] Effendy, N. (1998). Keperawatan Kesehatan Masyarakat, Jakarta : EGC.

[3] Departemen Kesehatan RI, (1997). Petunjuk Pengolahan dan Pemanfaatan Data SP2TP. Jakarta.

[4] Shalahuddin, Muhammad dan Rosa Ariani S. (2011). Modul Pembelajaran Rekayasa Perangkat Lunak Trstruktur dan Berientasi Objek, Bandung: Modula.

[5] Suhendar, A. dan Gunadi, H. (2002). Visual Modelling Menggunakan UML dan Rational Rose, Bandung: Informatika.

[6] Sholiq. (2006). Permodelan Sistem Informasi Berorientasi Obyek dengan UML, Yogyakarta : Graha Ilmu. 40-105.

[7] Nugroho, Adi. (2011). Perancangan dan Implementasi Sistem Basis Data, Yogyakarta: Andi 